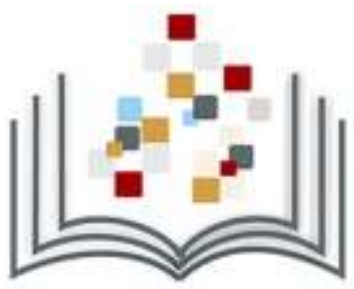

\title{
REVISTA BRASILEIRA DE ODONTOLOGIA: DO PASSADO AO FUTURO - OBSTÁCULOS E CONQUISTAS
}

Bruna Lavinas Sayed Picciani ${ }^{1^{*}}$ Luciana Manta Brício Pinhel ${ }^{1}$, Cíntia de Assis ${ }^{1}$, Alexandre de S. Rodrigues ${ }^{1}$, Ivan do Amaral Pereira ${ }^{1}$, Geraldo de Oliveira Silva-Júnior ${ }^{1}$

${ }^{1}$ Associação Brasileira de Odontologia - Rio de Janeiro (RJ) - Brasil

*Autor correspondente: scientificeditor@gmail.com

\section{Como citar:}

PICCIANI, Bruna L. S. et al. Revista brasileira de odontologia: do passado ao futuro obstáculos e conquistas. In: WORKSHOP DE EDITORAÇÃO CIENTÍFICA, 9., 2016, São

Paulo. Anais... São Paulo: Associação Brasileira de Editores Científicos, 2016. p. 30-32 DOI: http://dx.doi.org/10.21452/wec.IXwec.2016.0006

\section{INTRODUÇÃO}

A Revista Brasileira de Odontologia (RBO) é um periódico online, aberto, especializado e destina-se à publicação de artigos originais de pesquisa, revisões de literatura, comunicações breves, cartas ao editor, relacionados à odontologia ou disciplinas correlatas. Dirigida à classe odontológica há 73 anos, é uma publicação trimestral e editada pela Associação Brasileira de Odontologia - Seção Rio de Janeiro.

Nestes 73 anos de existência, a RBO manteve continuamente sua publicação, passando por diversas modificações, buscando se adequar à realidade da odontologia brasileira. A RBO por muitos anos foi considerada a principal fonte de literatura científica destinada à classe odontológica e, somente em 2008, passou a ser online, utilizando o Sistema Eletrônico de Editoração de Revistas (SEER). Deste período até 2016, poucas mudanças foram realizadas, tornando-se uma revista com baixo índice de submissão e de rejeição; além do longo período entre a submissão e publicação. Em 2016, após a eleição do novo conselho editorial, a RBO vem sofrendo grandes mudanças estruturais para competir com as diversas revistas da área odontológica, entretanto, muitos obstáculos ainda precisam ser superados, como a internacionalização e a indexação em bases de renome. Diante deste contexto, o objetivo deste estudo é relatar a história da Revista Brasileira de Odontologia, retratando as mudanças, conquistas e obstáculos dos seus 73 anos de existência.

\section{METODOLOGIA}

As informações foram coletadas pelos editores, bibliotecária e jornalista da RBO no Museu de Odontologia Sales Cunha da Associação Brasileira de Odontologia Seção Rio de Janeiro (ABO-RJ), em publicações anteriores da RBO e jornais da ABORJ e através do sistema SEER. O conjunto de dados foi sintetizado para estruturação dinâmica de toda história da RBO.

\section{RESULTADOS}

Em 1943, no contexto caótico da Segunda Guerra Mundial, dois cirurgiõesdentistas, Drs. Antônio Leme Júnior e Homero Coutinho fundam a RBO, onde o primeiro editorial relata sobre a gravidade da situação mundial e o papel da odontologia. Segundo o editorial: "A Odontologia assim como a Medicina tem a função primordial de 
criar e manter o mais alto patrimônio nacional - o homem." Apenas em 1946, foi realizada a doação dos direitos dos proprietários da Revista para ABO-RJ.

Nas décadas de 40 e 50, a revista era bimestral, dividida por departamentos da Associação, onde muitos comunicados e anúncios eram publicados, servindo de principal fonte de comunicação entre os dentistas cariocas. Fato interessante é que os dentistas recebiam por publicação, pois se entendia que o esforço para escrever o artigo deveria ser recompensado.

Nas décadas de 60 e 70, a revista adquiriu, em decorrência de sua periocidade bimestral, status científico e reconhecimento acadêmico, onde já havia um colégio de consultores para os artigos e toda divisão da RBO era por artigos de autores; substituindo a divisão por departamento.

Nas décadas de 80 e 90, a RBO continuou bimestral, entretanto, adquiriu um layout mais científico e moderno, tentando sobreviver à crise econômica pós-ditadura, através de vendas de anúncios. A partir de 2000, a revista é publicada toda em cores, obtendo uma cara nova e moderna.

Somente em 2008, foram dados os primeiros passos para a criação da RBO online. O primeiro passo foi a escolha da ferramenta para dar seguimento ao projeto, optou-se pelo Sistema Eletrônico de Editoração de Revistas (SEER). Por ser um software livre, que minimiza custos, além de oferecer uma gama de possíveis mudanças na estrutura do sistema. A outra etapa foi a participação no treinamento realizado pelo Instituto Brasileiro de Informação em Ciência e Tecnologia (lbict) pelo analista de sistema e pela bibliotecária, possibilitando a utilização do sistema e seu manuseio. A equipe com este projeto almejava traçar a estrutura da revista, de acordo com o público que se espera atingir; definir a equipe envolvida e suas funções; definir os critérios para avaliação dos artigos, bem como os prazos para avaliação; manter a periodicidade; informar prazos ao corpo editorial; manter uma relação com o autor, informando em que situação encontra-se seu artigo; definir os locais onde o mesmo estará disponível; registrar o periódico no ISSN e submeter sempre o periódico às instituições avaliadoras, são as etapas do processo de elaboração da revista.

Apesar de todo esforço que trouxe grande visibilidade a $\mathrm{RBO}$, muitas revistas foram surgindo no meio científico, gerando um declínio no número de submissões, o que impactou diretamente na periodicidade da revista, que passa a ser semestral em 2005. Ademais, a dificuldade financeira em manter a impressão e envio de 20.000 exemplares, bimestralmente, contribuiu para redução da periodicidade. Entretanto, a equipe muito engajada e acreditando no sucesso da RBO, continuou trabalhando em prol de melhorias da mesma, conseguindo a indexação em algumas bases, como: Index Dental to Literature, Scirus for Scientific Information Only, Ulrich's Directory Periodicals, $B B O$, Lilacs e Latindex; refletindo diretamente no Qualis da revista.

Em 2016, uma nova equipe editorial assume a RBO, com a proposta de elevar a qualidade deste periódico, propondo grandes mudanças. Como principais propostas alcançadas, destacamos: 1. Reformulação do corpo editorial com profissionais qualificados, com lattes atualizados e com $20 \%$ de afiliação estrangeira; 2 . A revista passa a ser trimestral e on-line com 15 artigos originais e/ou de revisão de literatura em cada volume; 3. Inserção de DOI; 4. Sugestão de envio de artigos na língua portuguesa e inglesa; entretanto, em 2017, será obrigatório ambas as línguas; 5 . Reestruturação das normas aos autores e processo de revisão por pares; 6 . Divisão do sumário e da revista por tipo de artigo; 7. Diminuição do tempo entre a submissão e aceite do artigo.

A tabela abaixo demonstra a evolução da revista de 2008 até 2016, baseando-se no número de submissões, aceites e tempo entre a submissão e publicação. 


\begin{tabular}{|c|c|c|c|c|c|c|c|c|c|}
\hline DADOS & 2008 & 2009 & 2010 & 2011 & 2012 & 2013 & 2014 & 2015 & 2016 (Vol. 1 e 2) \\
\hline $\begin{array}{l}\text { ARTIGOS } \\
\text { SUBMETIDOS }\end{array}$ & 31 & 66 & 67 & 89 & 79 & 59 & 53 & 57 & 102 \\
\hline $\begin{array}{l}\text { ARTIGOS } \\
\text { ACEITOS }\end{array}$ & 31 & 57 & 60 & 66 & 69 & 45 & 44 & 32 & 29 \\
\hline $\begin{array}{l}\text { TEMPO ENTRE } \\
\text { SUBMISSÃO } \\
\text { PUBLICAÇÃO } \\
\text { (dias) }\end{array}$ & 130 & 175 & 123 & 64 & 113 & 138 & 137 & 183 & 40 \\
\hline
\end{tabular}

Como metas principais destacamos a internacionalização e indexação da revista nas principais bases científicas, impactando diretamente no aumento do número de citações dos artigos. Atualmente, estas metas constituem o principal desafio dos editores, sendo necessário cumprir exigências para adequação do periódico. Os autores buscam revistas já indexadas com maior fator de impacto, sendo a RBO uma opção para artigos em português ou para artigos não aceitos nestas revistas. Então, como podemos receber artigos impactantes? Como convencer os autores a publicarem em inglês? Estamos realizando divulgação maciça das melhorias da RBO em busca de convencer os autores que vale a pena abraçar esta ideia, de transformar um periódico tradicional da odontologia brasileira em referência de publicações de excelência.

\section{CONCLUSÕES}

A RBO é uma das revistas mais tradicionais da odontologia que se mantêm no meio científico, devido ao empenho da equipe, que sempre busca a qualidade da produção científica na área odontológica. Apesar do desempenho inadequado mostrado pelos indicadores entre 2008 e 2015, atualmente, já é possível mensurar, por esses mesmos indicadores, a melhoria da qualidade da RBO, que mudou o seu perfil para se adequar ao cenário de publicações de excelência. Entretanto, alguns obstáculos ainda precisam ser vencidos para inserir a RBO no cenário das melhores revistas na área odontológica. Espera-se com as constantes mudanças, futuramente, escrever uma nova história, rumo à internacionalização e indexação.

PALAVRAS-CHAVE: Revista Brasileira de Odontologia. RBO. Odontologia. 